\title{
Commercial filming of prehospital patient care
}

\author{
P D Godfrey, J D Henning
}

Emerg Med J 2007;24:851-853. doi: 10.1136/emj.2007.049577

Commercial filming of patients in the hospital and now the prehospital environment is becoming increasingly common. Television programmes that focus on medical emergencies with real footage of events remain highly successful and can make compelling viewing for both medical professionals and the general public alike. Recently several commentators have questioned the ethical aspects of filming in hospital emergency departments, and noted the lack of available evidence. This article reviews commercial filming and its impact in the prehospital environment and examines the ethical implications and current guidance in this unique setting.

M edicine has long been a favourite theme for the makers of television programmes. Ever since 1957 when the UK first broadcast the medical drama Emergency - Ward 10, the format has thrived worldwide with countless spin-offs. ${ }^{1}$ Half a century later and the TV schedules remain full of similar programmes from both home and abroad. The medical profession has taken only a passing academic interest in TV medical dramas, with the publication of some studies that highlighted overoptimistic portrayals of certain disease processes or medical interventions. ${ }^{23}$

In the 1980s, "real life" television dramas gained in popularity and the medical documentary was born, becoming a regular feature by the mid 1990s. Early medical documentaries focused on paediatric care and hospital based emergency care. As the medical profession's interest in prehospital emergency care has taken off, the cameras followed on to ambulances and helicopters. Instead of actors we now regularly see real people delivering or receiving medical care, and this raises questions as to whether patients' best interests are being served by filming their treatment. These concerns now require further academic scrutiny.

\section{COMMERCIAL FILMING OF PATIENT CARE}

See end of article for authors' affiliations

\section{Correspondence to:} Dr P D Godfrey, Great North Air Ambulance, Northumberland Wing, The Imperial Centre, Grange Road, Darlington, DL1 $5 \mathrm{NQ}$, UK; philgods@gmail. com

Accepted 26 August 2007
Filming of doctors and patients is not a recent phenomenon $^{4}$ and may be done for several reasons, including to aid patient assessment, to monitor treatment effects, for medical training, for research, for medico-legal purposes, and for commercial motives. Commercial filming in medicine encompasses programming such as news broadcasts, traditional scripted documentaries, and more recently the "fly-on-the-wall" documentary. ${ }^{5}{ }^{6}$ The popularity of the latter is thought to be due to the availability of cheap, small video cameras, low production costs and high ratings appeal. ${ }^{7}$ Table 1 lists a sample of emergency and prehospital-based documentaries from the UK and USA.

As the success of the documentary format rolled over into the 21 st century, new programmes arrived that pushed the boundaries further. As a result several commentators began to question the ethical and legal issues of filming patients in such circumstances.. ${ }^{58}$ As early as 1995, the General Medical Council (GMC) issued guidance entitled Filming patients for television programmes, which emphasised the need for patient consent, and stated that "(doctors)...must ensure that the interests and well being of patients are preserved, and take precedence over the public interest in the making of a television or other programme...". ${ }^{9}$

\section{FILMING IN THE PREHOSPITAL \\ ENVIRONMENT}

The prehospital environment creates some unique challenges which can impact on the filming process. Compared to a hospital emergency department, it is a less controllable setting and resources are more limited. Patient care usually takes place at the scene of the emergency, putting safety issues high in the mind of all prehospital care providers. As the first point of patient contact, providers have very limited background information and have to make clinical decisions rapidly. Transporting patients who are sometimes critically ill requires constant vigilance and patient monitoring systems are not as reliable as those in hospital. ${ }^{10}$

A film crew working on a hospital based documentary will usually consist of a number of camera operators, sound and lighting engineers, interviewers and directors. Time may allow for more scripted elements within the show, and there is usually ample opportunity to discuss the details of filming with patients beforehand and obtain written informed consent. A typical film crew working in the prehospital environment consists of one person with a portable video camera, who arrives at the scene of the emergency at the same time as the care provider, either by ambulance, medical car or helicopter. Although guidelines are always agreed beforehand, the filming itself is less controllable in this setting. While on camera, paramedics and prehospital doctors will feel there is additional scrutiny of their actions, adding to the pressure in an already stressful environment. ${ }^{6}$

Helicopter emergency medical service (HEMS) prehospital care merits further consideration when discussing prehospital filming. Many doctors and paramedics currently working on helicopters have

Abbreviations: BMA, British Medical Association; CRM, crew resource management; GMC, General Medical Council; HEMS, helicopter emergency medical service; SAEM, Society for Academic Emergency Medicine 
Table 1 Medical documentaries in the UK and USA

\begin{tabular}{ll}
\hline UK & USA \\
\hline Jimmy's (ITV, 1995-1996) & ER: The real drama (A\&EN 1995) \\
Children's hospital (BBCl 1998) & Trauma: Life in the ER (TLC, 1997- \\
& 2002) \\
Trauma team (ITV, 1999-2001) & Paramedics (Discovery, 1999-2001) \\
The Golden Hour (ITV, 2005) & Doctor's diaries (BNN, 2002) \\
Trauma (BBC1, 2005) & Code Blue (TLC, 2002) \\
City Hospital (BBCl, 1999-) & Chopper Rescue (Discovery, 2005) \\
Trauma Uncut (BBC3, 2005-) & The Critical Hour (Discovery, 2003- \\
& 2006) \\
Emergency (Discovery 2006-) & Untold Stories of the ER (TLC, 2005-) \\
\hline
\end{tabular}

undergone an intensive period of training which, as well as augmenting their knowledge of prehospital care, includes crew resource management (CRM), aviation safety, navigation skills and multi-agency working. ${ }^{11}$ As an observer, the film maker receives a safety brief, but does not gain the same level of training. The pilot and crew must therefore exercise extra vigilance in these circumstances, which will add to the long list of distractions. The patients seen in HEMS work will usually be more seriously ill or injured than in other areas of prehospital care and some of these patients will lack the capacity to consent. This raises important ethical issues which, to date, have not been addressed in the prehospital environment.

\section{IS COMMERCIAL FILMING IN THE PATIENTS' INTERESTS?}

It is difficult to argue that commercial filming of patients in the prehospital environment actually benefits the individual. It should be remembered that the primary motivations for the programme makers are to entertain and educate the viewers. However, some suggest that patient care may be improved if doctors and paramedics are under the scrutiny of a camera, in that they may be more attentive, professional and courteous. Some patients may even welcome the process and see it as an opportunity to get on television. ${ }^{5}$

Good medical practice (2006) states that the duties of a doctor include to "protect and promote the health of patients and the public". ${ }^{12}$ One may then argue that the educational benefits to society as a whole go some way to justifying the practice. The trailblazers can also claim to be demystifying these aspects of healthcare and hence promoting an environment where people seek appropriate care. A number of HEMS operators are charity funded and will argue that the publicity gained helps increase donations, with the money going directly into patient care.

\section{ETHICAL ISSUES AND THE CONSENT PROCESS}

Medical ethics encompasses beneficence, non-maleficence, autonomy and justice. ${ }^{13}$ As noted earlier, the role of commercial filming in patient beneficence is limited, and it can be argued that the mere presence of a film crew causes distraction and potential maleficence. Autonomy may also be compromised, particularly when filming severely ill or injured patients, because of an unreliable consent process. There are also concerns that filming is an invasion of patient privacy and compromises their dignity. The only study in this field was performed in an emergency department in the USA and looked at patient and provider attitudes to commercial filming. ${ }^{14}$ The researchers found that healthcare providers rated invasion of patient privacy higher than patients rated their own invasion of privacy, and that it had no effect on patient satisfaction. They concluded that commercial filming has little measured impact in these respects.
In regards to consent, both the British Medical Association (BMA) in the UK and the Society for Academic Emergency Medicine (SAEM) in the US highlight the need for a dual consent process - the consent to being filmed which is obtained at the time of first patient contact, and the consent for dissemination of the subsequent recording which is sought at a later stage. ${ }^{15}{ }^{16}$ At first glance, the consent process appears reasonably clear cut for competent adult patients. However, gaining true informed consent in the emergency setting is not a straightforward process. Patients will be approached for consent to being filmed at a time when they are acutely unwell, either through disease or injury. They will have limited time to consider the request and may feel compelled to agree because of their vulnerable position. It is important patients are reassured that by withholding consent, their treatment will be unaffected.

\section{FILMING PATIENTS WHO ARE UNABLE TO CONSENT}

This category of patients may include children, those with a pre-existing condition that affects their capacity to consent and, particularly in the prehospital environment, those who are incapacitated by severe illness or injury.

The GMC publication Seeking patient's consent: the ethical considerations, provides detailed guidance on obtaining consent, including the process for those who lack capacity. ${ }^{17}$ This document provides a good framework, but is specific for medical investigations and treatment; something which commercial filming cannot claim to be.

With filming becoming increasingly common, the GMC published Making and using visual and audio recordings of patients. ${ }^{18}$ Specific paragraphs within the document refer to filming for use in public media which stress the need for "written patient consent, whether or not you consider the patient to be identifiable". They also advise "particular vigilance in recordings of those who are unable to give permission themselves. You should consider whether patients' interests and well-being, and in particular their privacy and dignity, are likely to be compromised by the recording, and whether sufficient account has been taken of these issues by the programme makers".

Similar guidance was issued by the BMA ethics committee in 2004 in Taking audio and visual images of patients. ${ }^{15}$ They comment "written permission must be obtained, irrespective of whether the image is considered to be anonymous. Where consent to making or using images of patients is not available because a patient lacks capacity, recordings may be made where this is not contrary to the patient's interests and authorization is given by parents or people close to the patient. No use must be made of the recording where it is against the interests of the patient. Where the incapacity is temporary, consent must be sought once the patient regains capacity". This guidance suggests that the filming patients without capacity can occur, with the consent process deferred until capacity is regained.

In 2005, the Department of Health published Guidance on filming in the NHS. ${ }^{19}$ This comments on the rise of filming in hospitals, adding "This is to be welcomed: TV, DVD and video are excellent ways of giving people a real insight into how the health service works." As a cautionary note, they add there is "...a duty of care to protect patients' well-being and right to privacy, and to make sure that filming does not interfere with their care or have any negative effects". In the document they provide a model consent form for patients who are to be filmed and they specifically include a form for those who lack the capacity to consent, to be completed by the care provider.

Guidance in the USA on this issue is conflicting. The SAEM believe "Image recording by commercial entities does not provide benefit to the patient and should not occur in either the out-of-hospital or emergency department setting". ${ }^{16}$ Similarly, 
the American College of Emergency Physicians discourages the filming of television programmes in emergency departments except when patients and staff members can give fully informed consent prior to their participation. ${ }^{20}$ The council on ethical and judicial affairs for the American Medical Association advocates using dramatic re-enactments with actors "instead of violating patient privacy". ${ }^{21}$

However, the Joint Commission, the predominant standardsetting and accrediting body in US healthcare, states: "In a situation where the patient is comatose or otherwise unable to give informed consent and no surrogate decision maker is available, the hospital may film or videotape itself or retain another to film or videotape patient care activities within a policy stating informed consent is required before that patient's film or videotape can be used for any purpose" ${ }^{\prime 2}{ }^{22}$

Regulations from the broadcasting watchdogs are less detailed and appear less restrictive. Within the Code of Practice for the Press Complaints Commission, a paragraph refers to invasion of privacy and puts the onus on editors to justify any intrusion without consent. ${ }^{23}$ Guidance from OFCOM recognises that filming in these situations may infringe privacy but says "appropriate decisions can be made in an edit suite in the cold light of day". ${ }^{24}$ For patients who agree to be filmed at the time but later withhold their consent for it to be broadcast, reputable programme makers agree not to use the footage, and will destroy it at the patient's request.

The Human Rights Act 1998 may have implications for filming because it makes it unlawful for public authorities "to act in a way that is incompatible with a Convention right". ${ }^{25}$ Article 3 of the Act prohibits torture, inhuman or degrading treatment, or punishment. The European Court has previously established that medical treatment without consent could, in extreme circumstances, be considered inhuman or degrading. However, the threshold set by the courts is high and it is unlikely that filming without prior consent would be sufficiently serious to breach this right.

Of more relevance is Article 8, which is concerned with the right to respect for private and family life. Potentially, a patient filmed while unconscious or one who had agreed to filming following inadequate informed consent may later suggest that this right was breached. To date, commercial filming of patients without consent has not been tested in the courts and no case law currently exists for this specific situation.

\section{INFORMATION GOVERNANCE}

Ambulance services have a duty to follow National Health Service guidance which encompasses the Data Protection Act 1998 and other related legislation. ${ }^{26}$ When patient information is to be shared with non-NHS organisations (including television companies), ambulance trusts must ensure that the information will continue to be handled in a secure and confidential way. Furthermore, filming will itself create sensitive patient information and Caldicott guardians need to be satisfied that the footage is managed appropriately thereafter.

\section{THE FUTURE}

While evidence about prehospital filming and its effect on patients remains scarce and public demand for the medical documentary remains high, it is likely that the process will remain widespread for the foreseeable future. Proponents will claim that the greater good is being served by continuing the practice. Clinicians and programme producers can also point to ethical guidance from the UK and the USA, which allows for the consent process for filming to be deferred until after the fact in those who lack capacity at the time. Well designed studies which seek to determine what impact commercial filming has on patient care in this environment are now overdue.

\section{Authors' affiliations \\ P D Godfrey, J D Henning, Great North Air Ambulance, Darlington, UK}

Competing interests: Commercial filming is currently ongoing at the Great North Air Ambulance and a study into its effects is underway.

\section{REFERENCES}

1 Anon. http://en.wikipedia.org/wiki/Emergency_Ward_10.

2 Casarett D, Fishman JM, MacMoran HJ, et al. Epidemiology and prognosis of coma in daytime television dramas. BMJ 2005;331:1537-9.

3 Diem SJ, Lantos JD, Tulsky JA. Cardiopulmonary resuscitation on television. Miracles and misinformation. N Engl J Med 1996;334:1578-82.

4 Goodenday LS, Carlsson E. Movie filming of patients and patients' records for teaching and clinical use. J Med Educ 1968;43:859-60.

5 Geiderman JM, Larkin GL. Commercial filming of patient care activities in hospitals. JAMA 2002;288:373-9.

6 Marco CA, Larkin GL, Silbergleit R. Filming of patients in academic emergency departments. Acad Emerg Med 2002;9:248-50.

7 Grimshaw A. Teaching visual anthropology. Notes from the field. Ethnos $2001 ; 66: 237-58$.

8 Geiderman JM. Fame, rights and videotape. Ann Emerg Med 2001;37:217-9

9 General Medical Council. GMC guidance on filming patients for television programmes. Audiovisual Media in Medicine 1995;18(4):171. http://www.gmc-uk.org/guidance/current/index.asp.

10 Morley AP. Prehospital monitoring of trauma patients: experience of a helicopter emergency medical service. Br J Anaesth 1996;76:726-30.

11 Helicopter Emergency Medical Service. HEMS Crew Course http:// www.greatnorthairambulance.co.uk/trauma/training.php.

12 General Medical Council. Good medical practice. London: GMC, 2006, http:// www.gmc-uk.org/guidance/good_medical_practice/index.asp.

13 Gillon R. Medical ethics: four principles plus attention to scope. BMJ 1994;209: 184.

14 Rodriguez RM, Dresden GM, Young JC. Patient and provider attitudes toward commercial television film crews in the emergency department. Acad Emerg Med 2001;8:740-5.

15 British Medical Association. Taking and using visual and audio images of patients. London: BMA, June 2004, http://www.bma.org.uk/ap.nsf/Content/ AVrecordings.

16 Society for Academic Emergency Medicine. Filming of emergency patients. Position statement by the Society for Academic Emergency Medicine. http:// www.saem.org/saemdnn/AboutSAEM/Governance/PositionStatements/ FilmingofEmergencyPatients/tabid/178/Default.aspx.

17 General Medical Council. Seeking patients' consent: the ethical considerations. London: GMC, 1998, http://www.gmc-uk.org/guidance/current/library/ consent.asp.

18 General Medical Council. Making and using visual and audio recordings of patients. J Audiovisual Media Med 2002;25:165-7. http://www.gmc-uk.org/ guidance/current/library/making audiovisual.asp.

19 Department of Health. Guidance on filming in the NHS. London: DoH. http:// www.dh.gov.uk/en/Publicationsandstatistics/Publications/ PublicationsPolicyAndGuidance/DH 4124294.

20 American College of Emergency Physicians. Filming in the emergency department. Policy statement by ACEP board of directors. February 2002. http://www.acep.org/webportal/PracticeResources/PolicyStatements/ethics/ FilmingED.htm.

21 American Medical Association. Ethics of physician participation in reality television for entertainment council on ethical and judicial affairs for the American Medical Association. http://www.ama-assn.org/amal/pub/ upload/mm/369/ceja_recs_2i05.pdf.

22 The Joint Commission. Patient rights and informed consent when videotaping or filming. http://www.jointcommission.org/AccreditationPrograms/Hospitals/ Standards/FAQs/Ethics+Rights+Responsibilites/Individual+Rights/ informed_consent.htm.

23 Press Complaints Commission. Code of practice. http://www.pcc.org.uk/cop/ practice.html.

24 OFCOM. Guidance on privacy. http://www.ofcom.org.uk/tv/ifi/guidance/ bguidance/guidance8.pdf

25 Hewson B. Why the human rights act matters to doctors. BMJ 2000;321:780-1.

26 Department of Health. Confidentiality: NHS code of practice 2003. http:// www.dh.gov.uk/en/Publicationsandstatistics/Publications/PublicationsPolic yAndGuidance/DH_4069253. 